\title{
Residues of Organochlorinated Pesticides in Soil from Tomato Fields, Ngarenanyuki, Tanzania
}

\author{
${ }^{1}{ }^{*}$ CHARLES KIHAMPA; ${ }^{1}$ RUBHERA RAM MATO $;{ }^{2}$ HUSSEIN MOHAMED \\ ${ }^{\mathrm{a}}$ School of Environmental Science and Technology, Ardhi University, P.O. Box 35176, Dar es Salaam, Tanzania; ${ }^{\mathrm{b}}$ Department of \\ Environmental and Occupational Health, Muhimbili University of Health and Allied Sciences, P.O. Box 65015, Dar es Salaam, Tanzania
}

\begin{abstract}
This work presents the concentrations of five pesticide residues, lindane, chlorpyrifos, endosulfan, $p, p^{\prime}$-DDE and $p, p^{\prime}$-DDD in soil samples collected from tomato fields in Ngarenanyuki, Tanzania. Endosulfan sulphate was detected in $100 \%$ of the sample analysed with mean concentration of $0.2407 \mathrm{mg} / \mathrm{kg} \mathrm{dw}$. Chlorpyrifos was detected in $87 \%$ of the samples with mean concentration of $0.1253 \mathrm{mg} / \mathrm{kg} \mathrm{dw} . p, p^{\prime}-\mathrm{DDE}$ and $p$, $p^{\prime}$-DDD were detected in 46 and $40 \%$ of the samples analysed with mean concentrations of 0.1482 and 0.154 $\mathrm{mg} / \mathrm{kg} \mathrm{dw}$, respectively. Lindane was the least detected pesticide. It was detected in 5 (33\%) of soil samples analysed with mean concentration of $0.2126 \mathrm{mg} / \mathrm{kg} \mathrm{dw}$. Low concentrations detected indicate the past usage of the pesticides. @ JASEM
\end{abstract}

The increased use of pesticides in agricultural activities has caused pollution of environmental compartments; soil, water and air. Their chemical properties such as high lipophilicity, bioaccumulation potential, long half-life in the environment, and potential to long-range transport, envisaged the chance to be found in water, soil or food even decades after their applications (Abbassy et al., 1999). Agricultural pesticides most often are applied as liquids, granules or seed sprayed/treated on the crop and/or the soil (Pimentel and Levitan, 1986). Extremely small percentage (less than $0.3 \%$ ) of the amount applied, goes into direct contact with or consumed by target pests, therefore $99.7 \%$ goes somewhere else in the environment (Pimentel, 1995). In Tanzania, most of the pesticides imported are used in agriculture activities (AGENDA, 2006). The aim of this work was to ascertain the levels of pesticide residues in soils from tomato fields at Ngarenanyuki.

\section{MATERIALS AND METHODS}

Study Area and Sample Collection: Ngarenanyuki is among the 17 wards in Arumeru District, Arusha City, Tanzania. It comprises of five villages (Uwiro, Ngabobo, Olkung'wado, Kisimiri chini and Kisimiri juu) located at the foot of Mt. Meru, north east of Arusha City ( $3^{\circ} 9^{\prime} 0^{\prime \prime}$ South, $36^{\circ} 51^{\prime} 0^{\prime \prime}$ East). 15 soil samples of $500 \mathrm{~g}$ each were randomly collected from 15 different locations at Uwiro village in January and February, 2009 (Figure 1). The soil samples were collected by using stainless spoon at the depth of 0 $15 \mathrm{~cm}$ (the root zone). The sampling procedures were conducted as described by Akerblom (1995). Chemicals: Chromatography grade dichloromethane, n-hexane, acetone, cyclohexane and ethyl acetate were used for sample preparation. Samples were quantified using pesticide standard mixture which had over $99 \%$ certified purity. Laboratory glassware were washed with detergents, rinsed with distilled water and acetone, and then dried in an oven at $110{ }^{\circ} \mathrm{C}$ overnight prior to use.

Extraction: Two sub-samples of $20 \mathrm{~g}$ each were subjected under different experimental treatments. For dry weight determination one sub-sample in a pre-weighed watch glass was heated in the oven at $105{ }^{\circ} \mathrm{C}$ to constant weight. Another sub-sample was put in a teflon stoppered flask $(250 \mathrm{ml})$ for pesticides extraction. $14 \mathrm{ml}$ of $0.2 \mathrm{M}$ ammonium chloride solution was added, the mixture swirled for $2 \mathrm{~min}$ and left to stand for $15 \mathrm{~min} .100 \mathrm{ml}$ of cyclohexane/acetone mixture $(1: 1 \mathrm{v} / \mathrm{v})$ was then added, the flask was tightly stoppered and vigorously shaken for $1 \mathrm{~min}$, and then less vigorously after every $10 \mathrm{~min}$ for $1 \mathrm{~h}$. The contents were then left to stand overnight. Intermittent shaking was continued the next day for two hours and then left to settle. Distilled water was cautiously added to the neck of the flask. The organic phase was pipetted into an E-flask containing anhydrous sodium sulphate $(15 \mathrm{~g})$, swirled and left to stand for $15 \mathrm{~min}$. The contents were then decanted through a plug of glass wool into an evaporation flask. The remaining sodium sulphate was rinsed with $20 \mathrm{ml}$ of acetone/cylohexane mixture and decanted through the same glass wool. The resulting extract was concentrated to less than $2 \mathrm{ml}$ using a rotary evaporator, the solvent was then changed to cyclohexane/ethylacetate $(1: 1 \mathrm{v} / \mathrm{v}, 1 \mathrm{ml})$ ready for clean up.

Clean up: This was done by glass column $(60 \mathrm{~cm} \mathrm{x}$ $22 \mathrm{~mm}$ ) chromatography packed with florisil (magnesium silicate), glasswool and anhydrous sodium sulphate. Cyclohexane: acetone $(9: 1 \mathrm{~V} / \mathrm{V})$ was added into the glass column and allowed to pass through drop by drop until very little was left on the upper part of the column. The sample concentrate was poured into the column and drained to make $3 \mathrm{ml}$ of the sample. This was then transferred into the Teflon cork vial and stored at $4{ }^{\circ} \mathrm{C}$ until analysis. 
Residues of Organochlorinated Pesticides.....

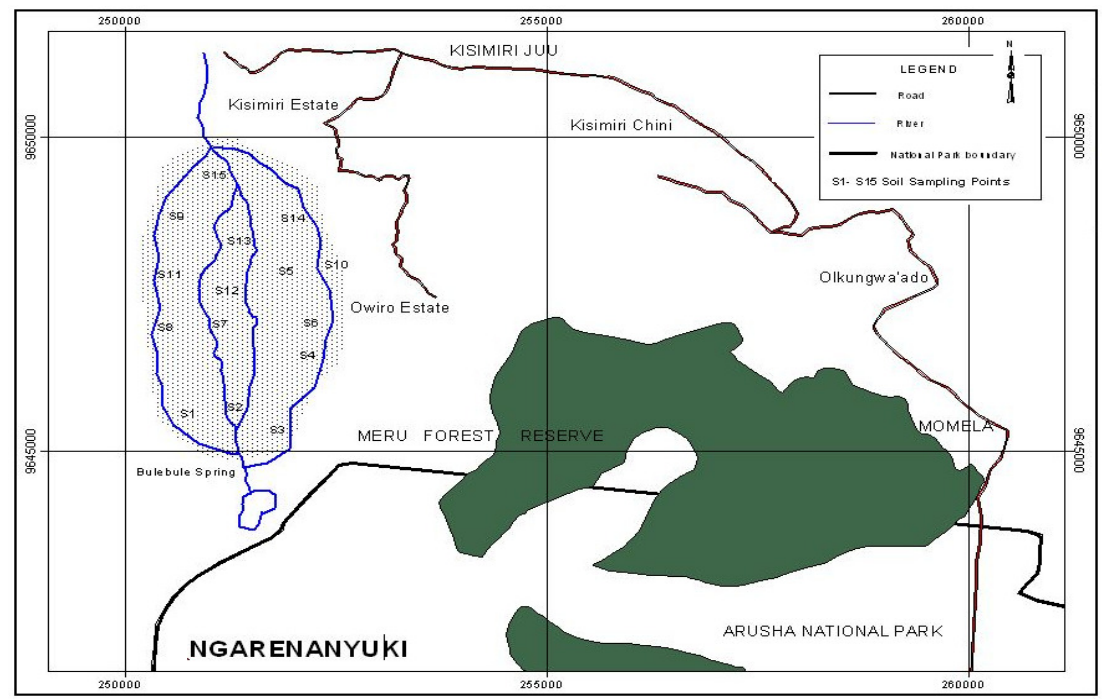

Fig 1.Map of Ngarenanyuki showing sampling sites at Uwiro Estates

Analytical Quality Assurance: A $100 \mathrm{ml}$ aliquot of each n-hexane, dichloromethane, cyclohexane, ethyl acetate and acetone was concentrated to $2 \mathrm{ml}$ and analysed to check the contamination from the solvents used. Two matrix blanks soil were obtained from a virgin land at Ardhi University. The results showed no significant peaks in the chromatograms of the blanks. Recoveries were estimated by spiking the matrix blank with standard pesticide solutions at concentrations ranging from 0.01 to $1.1 \mu \mathrm{g} / \mathrm{ml}$ for each analyte. The average of percentage recoveries \pm SD $(n=4)$ were as follows: Lindane $95.7 \pm 0.7 \%$, Chlorpyrifos $81.2 \pm 3.6 \%, p^{\prime}, p$ - DDE $94.5 \pm 1 \%$, and $p^{\prime}, p$-DDD $97.7 \pm 0.7 \%$. The results were not corrected for recoveries since they were within the normal acceptable range 70-120\% (Hill, 2000).

Sample Analysis: Analysis of the pesticide residues was done as described by Akerblom (1995). Gas chromatography Varian CP- 3800 equipped with ${ }^{63} \mathrm{Ni}$ Electron Capture (EC) detector, and capillary column WCOT FUSED SILICA $30 \mathrm{~m}$ x $0.32 \mathrm{~mm}$, coated with CP-SIL 8CB DF $1.0 \mu \mathrm{m}$ was used. Nitrogen was used as both a carrier and make up gas at a flow rate of $30 \pm 1 \mathrm{ml} / \mathrm{min}$. The temperature programme was held at $70^{\circ} \mathrm{C}$ for $1 \mathrm{~min}, 15^{\circ} \mathrm{C} / \mathrm{min}$ to $180{ }^{\circ} \mathrm{C}, 4{ }^{\circ} \mathrm{C} / \mathrm{min}$ to $230{ }^{\circ} \mathrm{C}$ for $15 \mathrm{~min}$. The injector and detector temperatures were $240{ }^{\circ} \mathrm{C}$ and $250{ }^{\circ} \mathrm{C}$, respectively. Identification of residues was effected by running samples and external reference standards in $\mathrm{GC}$ and then comparing the chromatograms.

\section{RESULTS AND DISCUSSION}

Table 1 shows concentrations of lindane, $p$, $p$ '-DDE, $p$, p'-DDD, chlorpyrifos and endosulfan sulphate detected in the soil samples. The concentrations ranged between $0.036-1.25 \mathrm{mg} / \mathrm{kg} \mathrm{dw}$. The highest value was found in sample S9 and lowest in sample S4. Endosulfan sulphate, was the most abundant residue detected in all $15(100 \%)$ samples analysed, with the concentration range $0.075-1.25 \mathrm{mg} / \mathrm{kg} \mathrm{dw}$ and mean of $0.24 \mathrm{mg} / \mathrm{kg} \mathrm{dw}$. Although endosulfan sulphate is susceptible to photolysis in the environment, it is expected to have a high occurrence in cultivated areas (Manirakiza et al., 2003). Dem et al., (2007) also reported high occurrence of 11 (74\%) endosulfan sulphate out of 15 soil samples from Sikasso areas in Mali. Endosulfan sulphate is a major degradation product of endosulfan, and is as toxic as parent compound (Jiang et al., 2009). Because of high toxicity, technical endosulfan was restricted in many countries including Tanzania. The high level of endosulfan sulphate detected implies that the pesticide has recently been used. This was also revealed by $83 \%$ of farmers interviewed during field visits that declared to have been using endosulfan under the trade name thionex.

Chlorpyrifos, was detected in 13 soil samples (87\%), with mean concentration of $0.125 \mathrm{mg} / \mathrm{kg} \mathrm{dw}$ and maximum of $0.172 \mathrm{mg} / \mathrm{kg} \mathrm{dw}$. The high detection frequencies of chlorpyrifos can be explained by the fact that it is moderately persistent in soils. The halflife of chlorpyrifos in soil is between 60 and 120 days, but can range from 2 weeks to over 1 year, depending on the soil type, climate, and other conditions (Wauchope et al., 1992).

DDT metabolites $p, p$ '-DDD and $p, p$ '-DDE were detected in $53 \%$ of the soil samples analysed with $\Sigma$ of DDT $(p, p$-DDD $+p, p-\mathrm{DDE})$ concentration of $2.27 \mathrm{mg} / \mathrm{kg} \mathrm{dw} . p, p$ '-DDD is sometimes used as a pesticide of its own under the trade name rothane and ISO approved name of TDE (Tomlin, 2000). $p$, p'DDD was detected in $47 \%$ of samples analysed with concentration ranging from bdl to $0.211 \mathrm{mg} / \mathrm{kg} \mathrm{dw}$ and mean concentration of $0.15 \mathrm{mg} / \mathrm{kg} \mathrm{dw}$. DDE is normally found in the environment as a result of contamination or breakdown of DDT. $p, p$ '-DDE was detected in 6 out of 15 samples analysed (40\%) with 
Residues of Organochlorinated Pesticides.....

mean concentration of $0.15 \mathrm{mg} / \mathrm{kg} \mathrm{dw}$, and 0.214 $\mathrm{mg} / \mathrm{kg} \mathrm{dw}$ and bdl being the highest and lowest concentrations, respectively. The occurrence of $p, p$ 'DDD and $p, p$ '-DDE in soil samples correlates with findings from farmers interviewed who claimed to have used DDT till late 1990s. DDD and DDE may last in the soil for a very long time, potentially for hundred of years (ATSDR, 2002) sticking strongly to soils and thus remain in the surface layers of soil. The persistence in the environment of these organochlorines have also been reported in other areas, for instance in China, DDE and DDD have been reported to be widely distributed in soil despite of their discontinued use since 1983 (Wu et al., 2007). Dem et al., (2007) also reported presence of $p$, $p$ '-DDE in soils and water from four cotton growing areas of Mali. In Tanganyika Sugar Cane plantations (TPC), Kilimanjaro, Tanzania, residues of organochlorine pesticides, aldrin, dieldrin, heptachlor epoxide, HCHs, endosulfans and DDTs were detected with mean concentrations ranging from 1.1 to 636.7 $\mu \mathrm{g} / \mathrm{l}$ despite of discontinued use (Hellar and Kishimba, 2005).

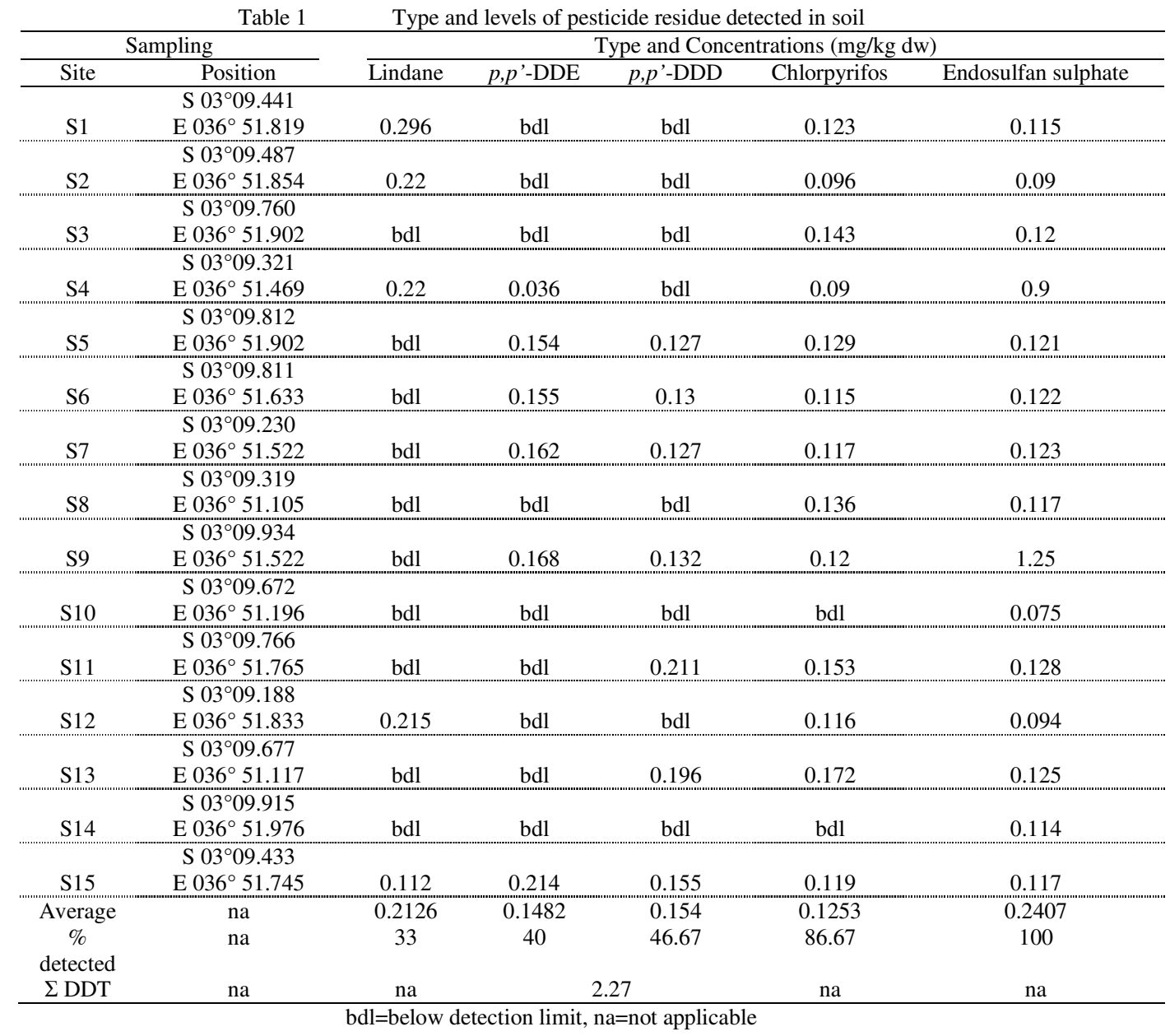

Soil concentrations of lindane depend on the method of application, soil composition and climatic conditions (Atlas and Giam, 1981). Although it was banned for use in several countries, lindane is still used extensively in many countries for the control of agricultural pests. Lindane like other organochlorine pesticide is highly persistent in most soils, with a field half-life of approximately 15 months (Atlas and Giam, 1981). In this study lindane was detected in 5 (33\%) out of 15 samples analysed with the highest concentration of $0.29 \mathrm{mg} / \mathrm{kg} \mathrm{dw}$ and mean concentration of $0.21 \mathrm{mg} / \mathrm{kg} \mathrm{dw}$. It was the least detected pesticide followed after $p$, $p$ '-DDE. The least detection of lindane can be explained in one hand to be not extensively used pesticides in Ngarenanyuki. It was not mentioned in farmer's interview as one of the pesticides used; therefore detection of lindane indicates the past usage.

Generally, the concentrations detected in this study compares with values reported in other countries in the world. Although the concentrations of pesticide residues reported under this investigation were low, soils pollution can play an important role in the global fate and distribution of pollutants. Soil can act as a sink of pesticides, from which they can be released into water or air, and may be taken up by plant roots, and bioaccumulate in the food chain to an extent higher enough to cause chronic adverse health effects to consumers. 
Residues of Organochlorinated Pesticides.....

Acknowledgement: Acknowledgement: We are gratefully acknowledging the inputs of Mr. Lutufyo Mwamtobe from the Department of Chemistry, University of Dar es Salaam, and Mr. Addo Ndimbo and Ramadhani Mbulume from the School of Environmental Science and Technology, Ardhi University for their invaluable technical assistance during the laboratory extraction and analysis.

\section{REFERENCES}

Abbassy, MS; Ibrahim, HZ; Abu El-Amayem, MM (1999). Occurrence of pesticides and polychlorinated biphenyls in water of the Nile river at the estuaries of Rosetta and Damiatta branches, North of Delta, Egypt. J Environ Sci Health 34: 255-267.

AGENDA (2006). A case study on trade and utilization of pesticides in Tanzania: Implications to stockpiling by AGENDA for environment and responsible development.

Åkerblom, M. (1995). Guidelines for environmental monitoring of pesticide residues for the SADC Region. SADC/ELMS, Monitoring Techniques Series.

Atlas E, Giam CS (1981). Global transport of organic pollutants, ambient concentration in the remote marine atmosphere. Science 211: 164-155.

ATSDR (Agency for toxic substances and disease registry) (1994). Toxicological profile for 4, 4'DDT, 4, 4'-DDE, 4, 4'-DDD (update), U.S. Department and Health Services, Public Health Services, Atlanta, GA.

Carson, RL (1962). Silent spring. Riverside Press, Cambridge, MA, USA.

Dem, SB; Cobb, JM; Mullins, ED (2007). Pesticides residues in soil and water from four cotton growing areas of Mali, West Africa. J Agri Food Environ Sci 1: 1-12.
Hellar, H; Kishimba, MA (2005). Pesticide residues in water from TPC sugarcane plantations and environs, Kilimanjaro region, Tanzania. Tanz J Sci 31: 13-22.

Hill, A (2000). Quality Control Procedures for esticide Residues Guidelines for Residues Monitoring in the European nion ( $2^{\text {nd }}$ edn). Document no. ANCO/3103/2000, European Commission.

Jiang, FY; Wang, TX; Jia, Y; Wang, F; Wu, HM; Sheng, YG; Fu, MJ (2009). Occurrence, distribution and possible sources of organochlorine pesticides in agricultural soil of Shanghai, China. J Haz Mater 170: 2-3.

Manirakiza, P; Akinbamijo, O; Covaci, A; Pitonzo, R; Schepens, P (2003). Assessment of organochlorine pesticides residues in African city farms: Banjul and Dakar case study. Arch Environ Contamin Toxicol 44: 171-179.

Pimentel D, Levitan, L (1986). Amounts applied and amounts reaching pests. Bioscience (36): 86-91.

Pimentel, D (1995). Amounts of pesticides reaching target pests. Environmental impacts and ethics. J Agr Environ Ethics 8: 17-29.

Tomlin, C (2000). The Pesticide Manual (12 $2^{\text {th }}$ edn). Crop Protection Publications: London.

Wauchope, RD; Buttler, TM; Hornsby, AG; Beckers, PWM; Burt, JP (1992). Pesticide properties database for environmental decision making. Rev Environ Contam Toxicol 123: 1-157.

Wu, N; Zhang, S; Huang, H; Shan, X; Christie, P; Wang, Y (2007). DDT uptake by arbuscular mycorhizal alfalfa and depletion in soil as influenced by soil application of non ionic surfactant. Environ Poll 5: 21-420. 